\title{
Differentiation of Deboned Fresh Chicken Thigh Meat from the Frozen- Thawed One Processed with Different Deboning Conditions
}

\author{
Young Sik Bae ${ }^{1}$, Jae Cheong Lee ${ }^{2}$, Samooel Jung ${ }^{1}$, Hyun-Joo Kim, Seung Yeop Jeon², \\ Do Hee Park', Soo-Kee Lee ${ }^{1}$, and Cheorun Jo* \\ Department of Agricultural Biotechnology, Center for Food and Bioconvergence and Research Institute \\ of Agriculture and Life Science, Seoul National University, Seoul 151-921, Korea \\ ${ }^{1}$ Department of Animal Science and Biotechnology, Chungnam National University, Daejeon 305-764, Korea \\ ${ }^{2}$ Korea Institute for Animal Products Quality Evaluation, Gunpo 435-010, Korea
}

\begin{abstract}
This study was performed to evaluate the quality characteristics of three deboned categories of chicken thigh meat: one which was slaughtered and deboned in the same plant (fresh); one which was slaughtered, deboned, frozen, and thawed in the same plant (frozen-thawed); and the last which was slaughtered in a plant, deboned in a different plant, but then transferred to the original plant (fresh-outside). Surface color, drip loss, 2-thiobarbituric acid reactive substances (TBARS) value, sensory evaluation, and total aerobic bacterial counts of the chicken samples were determined. Moreover, the torrymeter was used to measure the differences in freshness of the chicken meat. The surface color and the TBARS values did not show significant differences among the three categories. However, the total aerobic bacterial counts of fresh-outside and frozenthawed chicken meat were significantly higher than the fresh chicken meat on the first storage day, and the drip loss of frozen-thawed chicken meat was significantly higher than the fresh-outside and fresh chicken meat. In addition, the sensory evaluation of frozen-thawed chicken meat was significantly lower than the fresh-outside and fresh chicken meat. Torrymeter values were higher in fresh chicken meat than fresh-outside and frozen-thawed chicken meat during the storage period. These results indicate that the quality of frozen-thawed chicken meat is comparatively lower than the fresh chicken meat, and the torrymeter values can accurately differentiate the fresh-outside and frozen-thawed chicken meat from the fresh ones.
\end{abstract}

Key words: chicken thigh, fresh, frozen-thawed, deboning, torrymeter, differentiation

\section{Introduction}

Chicken meat is generally considered as the healthiest animal food because it is low in fat and cholesterol, but rich in protein (Choe et al., 2010). In addition, chicken is cheap and its consumption is not forbidden by any religion. The per capita consumption of chicken, both whole (Han et al., 2009) and deboned (Lee et al., 2012), is steadily increasing in Korea. With the increasing demand, the amount of chicken meat imported into Korea has increased by approximately two folds, from 58,000 tons in 2009 to 108,000 tons in 2011 (Korea Chicken Council, 2011).

Imported chicken meat in Korea is usually frozen and

\footnotetext{
*Corresponding author: Cheorun Jo, Department of Agricultural Biotechnology, Center for Food and Bioconvergence and Research Institute of Agriculture and Life Science, Seoul National University, Seoul 151-921, Korea. Tel: 82-2-880-4804, Fax: 82-2-873-2271, E-mail: cheorun@snu.ac.kr
}

much cheaper than fresh refrigerated ones. Freezing is an excellent method to preserve the quality of meat and fish for a long time (Sung et al., 2013). However, deterioration of meat quality, indicated by factors such as high drip loss, decreases in tenderness and water-holding capacity, is triggered by the freezing and thawing process (Jeong et al., 2011; Turhan et al., 2006). In addition, various enzymes such as lysozymes, lipases, and proteases are released by damaged cells (Ballin and Lametsch, 2008). Despite the fact that frozen-thawed meat is of low quality, some domestic vendors deceive customers by mixing it with fresh meat. This practice is illegal. The rule imposed by government to label the meat and indicate its origin does not dissuade these illegal vendors.

It is difficult to visually differentiate fresh meat or fish from frozen-thawed one. However, studies on different meat species reported that torrymeter measurement could distinguish fresh meat or fish from frozen-thawed one (Duflos et al., 2002; Jung et al., 2011; Sung et al., 2013). Harvesting physically damaged frozen-thawed meat or 
fish, makes its torrymeter value different from that of the fresh one (Lougovois et al., 2003). They also reported that the torrymeter is easy to use, highly sensitive, and portable.

The animal product grading system has had a good impact on the production, and processing sectors and on the consumers since its introduction in Korea (KREI, 2008). In Korea, the grading of chicken meat is not compulsory. Recently, however, the consumer demand for chicken meat quality grading has been increased dramatically. To obtain the quality grade, chicken meat must be fresh (not frozen before) and it should not pass $48 \mathrm{~h}$ after slaughter (Notification from MIFAFF, 2011-175). In case of chicken meat cuts, chicken must be slaughtered and deboned at the same plant to obtain the quality grade because quality change of chicken meat is expected while transported. Recently, some companies have requested the permit to grade meat that is slaughtered and deboned in different plants (fresh-outside) when a single plant is unable to run both processes.

It is difficult to differentiate fresh chicken meat cuts with frozen-thawed or fresh but deboned at a different plant (fresh-outside). Therefore, the objective of this study was to evaluate the reliability of torrymeter measurement in differentiating among the deboned fresh chicken thigh meat that was slaughtered and deboned in the same plant without freezing (fresh), chicken meat that was slaughtered, deboned, frozen, and thawed in the same plant (frozen-thawed), and fresh one that was slaughtered in one plant, transferred to another plant for deboning, and returned to original plant without freezing (fresh-outside). The quality parameters were also assessed.

\section{Materials and Methods}

\section{Sample preparation}

Chickens (Ross), which were reared in the same farm, and were fed the same feed, with an average weight of $1.5 \mathrm{~kg}$ ( $33 \mathrm{~d}$ of age, 10 chickens per treatment) were slaughtered at a local slaughter house (Cheonan, Korea). One day after slaughtering, fresh chickens were manually deboned in the same plant; and skinless thigh samples were packaged in low-density polyethylene material and stored in a refrigerator $\left(4^{\circ} \mathrm{C}\right)$. These were the fresh samples. To prepare the fresh-outside samples, after slaughtering, whole chickens were transferred to a different plant (Jincheon, Korea) for manual deboning. For transfer, the chickens were put in an ice-filled container that was driven by a refrigerated truck. The deboned skinless chicken thighs (fresh-outside) were aerobically packaged with the same low-density polyethylene material, returned to the original plant the next day, and stored in a refrigerator at $4^{\circ} \mathrm{C}$. Frozen-thawed samples were prepared by storing the skinless thigh meat packaged with low-density polyethylene in a deep freezer $\left(-40^{\circ} \mathrm{C}\right)$ for $29 \mathrm{~d}$. These samples were then individually thawed in cool water $\left(<10^{\circ} \mathrm{C}\right)$ for $2 \mathrm{~d}$ and transferred into a refrigerator $\left(4^{\circ} \mathrm{C}\right)$. This process is a typical practice in industry.

Surface color, lipid oxidation, and total aerobic bacterial count of the skinless thigh samples were determined on the first (the next day of deboning), third, and seventh day of storage at $4^{\circ} \mathrm{C}$. Torrymeter value was measured daily for $7 \mathrm{~d}$ and drip loss was measured after $7 \mathrm{~d}$ of storage.

\section{Surface color}

The color values of the chicken thigh samples were measured on the surface of samples by using a colorimeter (Spectrophotometer, CR-300, Minolta Inc., Japan). This instrument was calibrated with a black and a white reference tile. The values of lightness (CIE L*), redness (CIE $\left.a^{*}\right)$, and yellowness (CIE b*) were obtained. For each color, three measurements were taken from different locations on the surface of skinless thigh, and their average was determined. Each color value was analyzed by Spectra Magic Software (Minolta Inc., Japan).

\section{2-Thiobarbituric acid reactive substances (TBARS) value}

Lipid oxidation was determined as the TBARS value by using the method described by Jung et al. (2012). For this test, $3 \mathrm{~g}$ of meat was added to $9 \mathrm{~mL}$ of distilled water. This was followed by the addition of $50 \mu \mathrm{L}$ of butylated hydroxyanisol $(7.2 \%)$. The whole mixture was homogenized for $30 \mathrm{~s}$. One milliliter of the homogenate was transferred to a test tube, and $2 \mathrm{~mL}$ of TBA-TCA solution (20 $\mathrm{mM}$ TBA in $15 \%$ trichloracetic acid) was added to it.The tubes were heated at $90^{\circ} \mathrm{C}$ in a boiling water bath for 30 min, cooled, and centrifuged for $10 \mathrm{~min}$ at 2,090×g (Hanil Science Industrial Co., Korea). The absorbance of the supernatant was measured at $532 \mathrm{~nm}$ with a spectrophotometer (DU530, Beckman Instruments Inc., USA). TBARS value was reported as milligram of malondialdehyde per kilogram of meat.

\section{Total aerobic bacterial counts}

Five grams of the meat sample were mixed with sterile saline solution $(0.85 \% \mathrm{NaCl}, 45 \mathrm{~mL})$ for $30 \mathrm{~min}$, using a 
bag mixer (Model 400, Interscience, France). The mixture was then serially diluted. A series of decimal dilutions was prepared with sterile saline. Three agar plates were inoculated with $100 \mu \mathrm{L}$ of each of the serially diluted solution. These plates were prepared in triplicate, the dilutions were spread, and the plates were incubated at $37^{\circ} \mathrm{C}$ for $48 \mathrm{~h}$. After incubation, the microbial counts were determined and expressed as Log CFU/g.

\section{Drip loss}

The packaged chicken thighs were stored for $7 \mathrm{~d}$ at $4^{\circ} \mathrm{C}$, following which the drip loss was measured. This was done by weighing the samples and comparing their actual weights with the weight (original sample weight) measured on the first day of storage. The loss during thawing for frozen-thawed meat in cool water $\left(<10^{\circ} \mathrm{C}\right)$ for $2 \mathrm{~d}$ was not included in drip loss calculation. Drip loss was expressed as percentage, and it was calculated as follows:

Drip loss $(\%)=\{$ (original thigh sample weight - measured thigh sample weight) / original thigh sample weight $\times 100$

\section{Sensory evaluation}

Sensory evaluation was conducted by seven panelists. The panelists have experience on the sensory test of chicken meat at least six months. The meat samples $(40 \times 20 \times$ $10 \mathrm{~mm}$ ) were electrically grilled until the internal temperature reached to $72^{\circ} \mathrm{C}$. Preliminary testing was done on the fresh samples. Each meat samples were placed on coded white dishes and served to panelists with water for rinsing the oral cavity. The samples were labeled with random 3-digit numbers and provided to panelists in random order. The sensory parameters, namely, color, flavor, taste, tenderness, juiciness, and overall acceptability, were measured using a 9-point hedonic scale ( $1=$ extremely disliked, $5=$ moderately liked, $9=$ extremely liked). Each sensory parameter was measured three times on the third day of storage.

\section{Torrymeter value measurement}

The torrymeter (GR The Torry Freshness Meter, Distell Industries Ltd., UK) was used to evaluate the degree of freshness of chicken thigh meat stored at $4^{\circ} \mathrm{C}$. The torrymeter sends low electric current under $1 \mathrm{~mA}$ to the sample, which helps determine changes in the dielectric properties of the tissues (Duflos et al., 2002). The torrymeter gives a response ranging from 0 (advanced decomposition) to 16 (very fresh). A single measurement was obtained for each sample by applying the probe of the torrymeter on the sample surface. Electrodes were cleaned between measurements.

\section{Statistical analysis}

The whole experiment was performed in triplicates. Analysis of variance was calculated via the procedure of the General Linear Model by using SAS version 9.2 software. Duncan's multiple range test was conducted to determine the significant differences among the mean values of treatments $(p<0.05)$. The mean values and their standard errors (SEM) were also calculated.

$$
\begin{aligned}
y_{i j} & =\mu_{i}+\alpha_{i}+\varepsilon_{i j} \quad(i=1,2,3 ; j=1,2,3) \\
y_{i j} & =\text { the } j \text { observation on the } i \text { treatment } \\
\mu_{i} & =\text { grand mean } \\
\alpha_{i} & =\text { effect of } i \text { treatment } \\
\varepsilon_{i j} & =\text { random error }
\end{aligned}
$$

\section{Results and Discussion}

\section{Surface color}

When consumers buy meat, surface color is the most important factor considered by them (Fletcher, 1999). Bright red meat is highly preferred over the brown one, because the bright red color indicates that the meat is fresh. Meat color is dependent on $\mathrm{pH}$, temperature, premortem stress, age, and sex (Renerre and Labadie, 1993). During the freezing-thawing process, myofibrils shrink and exudates leak from them. These exudates may cause light scattering; however, there was no significant difference in $L^{*}$ value over the storage period (Table 1 ). The $a^{*}$ (redness) value of fresh chicken meat increased significantly over the storage period. Livingston and Brown (1981) reported that metmyoglobin reducing activity is very active and is quickly reduced to deoxymyoglobin. When this happens, the meat obtains a bloom color in fresh muscle. During storage, oxymyoglobin is converted into metmyoglobin by autoxidation, making the meat appeardarker (Ledward and MacFarlane, 1971). On the first day of storage, the $b^{*}$ value of frozen-thawed chicken meat was significantly higher than that of fresh and fresh-outside meat. This observation is in agreement with the findings of Sung et al. (2013) and is explained by the fact that the freeze-thaw cycle causes lipid oxidation and color instability (Dias et al., 1994). 
Table 1. Surface color, 2-tiobarbituric acid reactive substances (TBARS), total aerobic bacterial (TAB) count of chicken thigh meat processed with different deboning conditions

\begin{tabular}{|c|c|c|c|c|c|}
\hline & \multicolumn{4}{|c|}{ Storage (d) } & \multirow{2}{*}{$\mathrm{SEM}^{2}$} \\
\hline & Treatment $^{1}$ & 1 & 3 & 7 & \\
\hline \multirow{4}{*}{$\mathrm{L}^{*}$} & Fresh & 54.95 & 55.26 & 53.34 & 0.711 \\
\hline & Fresh-outside & 54.90 & 54.86 & 54.88 & 1.813 \\
\hline & Frozen-thawed & 56.26 & 58.41 & 56.59 & 1.128 \\
\hline & SEM $^{3}$ & 1.132 & 1.500 & 1.239 & \\
\hline \multirow{4}{*}{$a^{*}$} & Fresh & $5.91^{\mathrm{y}}$ & $7.03^{x y}$ & $8.11^{\mathrm{x}}$ & 0.465 \\
\hline & Fresh-outside & 5.69 & 8.61 & 8.25 & 0.826 \\
\hline & Frozen-thawed & 8.14 & 7.93 & 7.71 & 0.996 \\
\hline & SEM $^{3}$ & 0.800 & 0.756 & 0.824 & \\
\hline \multirow{4}{*}{$b^{*}$} & Fresh & $17.24^{b}$ & 17.83 & 17.88 & 0.511 \\
\hline & Fresh-outside & $16.60^{\mathrm{b}}$ & 18.43 & 17.59 & 0.535 \\
\hline & Frozen-thawed & $18.63^{\mathrm{a}}$ & 18.21 & 18.42 & 0.524 \\
\hline & SEM $^{3}$ & 0.340 & 0.476 & 0.693 & \\
\hline \multirow{4}{*}{ TBARS } & Fresh & 0.36 & 0.35 & 0.37 & 0.023 \\
\hline & Fresh-outside & $0.37^{y}$ & $0.39^{y}$ & $0.45^{\mathrm{x}}$ & 0.016 \\
\hline & Frozen-thawed & 0.46 & 0.47 & 0.48 & 0.057 \\
\hline & SEM $^{3}$ & 0.035 & 0.042 & 0.034 & \\
\hline \multirow{4}{*}{ TAB } & Fresh & $2.52^{\text {by }}$ & $3.62^{\mathrm{y}}$ & $7.03^{x}$ & 0.374 \\
\hline & Fresh-outside & $4.22^{\mathrm{ay}}$ & $4.91^{\mathrm{y}}$ & $7.17^{\mathrm{x}}$ & 0.254 \\
\hline & Frozen-thawed & $3.61^{\mathrm{az}}$ & $5.11^{y}$ & $7.36^{x}$ & 0.241 \\
\hline & SEM $^{3}$ & 0.207 & 0.351 & 0.310 & \\
\hline
\end{tabular}

${ }^{1}$ Fresh, chicken thigh meat slaughtered and deboned in the same plant and stored at $4^{\circ} \mathrm{C}$; Fresh-outside, chicken thigh meat slaughtered in a plant, deboned in a different plant, but transferred to the original plant and stored at $4^{\circ} \mathrm{C}$; Frozen-thawed, chicken thigh meat slaughtered, deboned, frozen at $-40^{\circ} \mathrm{C}$ for $29 \mathrm{~d}$, thawed with cool water, and stored at $4^{\circ} \mathrm{C}$.

${ }^{2}$ Standard error of the means $(n=9)$.

${ }^{3}(n=9)$.

${ }^{a, b}$ Different letters within the same column with the same parameter differ significantly $(p<0.05)$.

${ }^{\mathrm{x}, \mathrm{y}}$ Different letters within the same row differ significantly $(p<0.05)$.

\section{2-Thiobarbituric acid reactive substances (TBARS) value}

Lipid oxidation products cause the following effects: development of rancid flavor, discoloration, and acceleration of myoglobin oxidation. The aldehydic compounds, malondialdehyde and hydroxynonenal, are the major final products of lipid oxidation (Philippe et al., 2007). The TBARS value of frozen-thawed meat was significantly higher than that of fresh and fresh-outside meat (Table 1). During freezing, the cell membranes are damaged by ice crystals; these membranes then release pro-oxidants such as free iron (Benjakul and Bauer, 2001). The TBARSvalue of fresh and frozen-thawed chicken meat did not increase significantly on the seventh day of storage (Table 1). These results concord with the findings of Filgueras et al. (2010) who reported that the TBARS value of leg muscle of rhea was not significantly increased during airpackaged storage. On the other hand, the TBARS value of fresh-outside sample had increased significantly on the seventh day of storage. This may be attributed to the inevitable fluctuation in temperature during transportation and handling.

\section{Total aerobic bacterial (TAB) count}

On the first day of storage, fresh chicken meat showed significantly lower TAB counts than fresh-outside and frozen-thawed meat (Table 1). The TAB counts of frozenthawed meat significantly increased during the storage period, whereas those of fresh and fresh-outside samples increased only after the third day of storage $(p<0.05)$. Moisture leaked out of the meat during thawing. This moisture contained proteins, vitamins, and minerals, which are conducive to microbial growth (Leygonie et al., 2012). In this study, we considered meat as spoilt when the TAB counts was greater than $7 \mathrm{Log} C F U / g$ on the seventh day of storage.

\section{Drip loss and sensory evaluation}

The drip loss of frozen-thawed chicken meat (6.36\%) was significantly higher than that of fresh-outside (3.7\%) and fresh (4.59\%) samples (Fig. 1). Drip loss of meat is inevitable due to the isoelectric point of muscle proteins, 


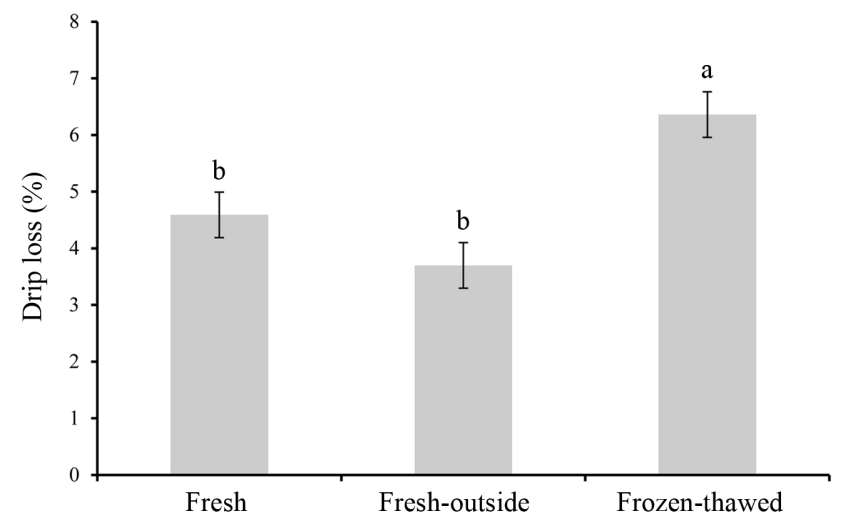

Fig. 1. Drip loss of chicken thigh meat processed with different deboning conditions after $7 \mathbf{d}$ of storage. ${ }^{a, b}$ Different letters among treatments differ significantly $(p<0.05)$.

the loss of adenosine triphosphate (ATP), proteolysis, and shrinking of the myofibrils during rigor mortis (HuffLonergan and Lonergan, 2005). In case of frozen-thawed chicken thigh meat, ice crystals can cause physical damage, cell destruction, and body fluid separation. After microscopic observation, Jung et al. (2011) reported that frozen-thawed breast fillets had larger spaces between their muscle fibers and their myofibrils had collapsed. Decreased water holding capacity of meat can be attributed to frozen storage and thawing (Vieira et al., 2009). Therefore, as expected, the drip loss of frozen-thawed chicken meat was more than that of fresh-outside and fresh samples.

As shown in Table 2, the color, flavor, taste, tenderness, juiciness, and overall acceptability values of fresh and fresh-outside samples were significantly higher $(p<0.05)$ than those of frozen-thawed samples, and the sensory panelists clearly noticed the differences between the frozenthawed chicken thigh meat and other samples. During thawing, water is released as the muscle fibers shrink. The fibers, therefore, become flaccid and tough or less tender (Leygonie et al., 2012). Therefore, frozen-thawed samples had low sensory scores. This is explained by the fact that tenderness plays an important role in the textural charac-

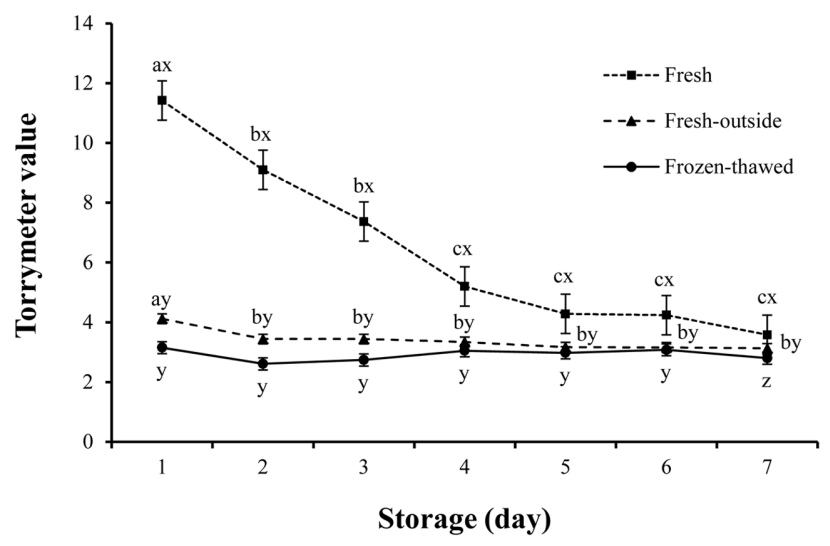

Fig. 2. Torrymeter value of chicken thigh meat processed with different deboningconditionsand stored for $7 \mathrm{~d} .{ }^{\mathrm{a}-\mathrm{c}} \mathrm{Dif}-$ ferent letters among storage days differ significantly $(p<$ $0.05)$. ${ }^{x-z}$ Different letters among treatments differ significantly $(p<0.05)$.

teristic of meat (Kim and Lee, 2003), and the drip contains many nutrients (Fischer, 2007).

\section{Torrymeter value}

The torrymeter value of fresh chicken meat (7.69) was significantly higher than that of fresh-outside (3.44) and frozen-thawed samples (3.14) at the first storage day (Fig. 2). This value of fresh chicken meat decreased steeply from the first to the fourth day of storage; after the fourth day, the decrease was more gradual while those of the freshoutside and the frozen-thawed chicken meat remained constant lower throughout the storage period. These findings concord with those of Jung et al. (2011); they reported that the torrymeter values of fresh chicken breast meat decreased significantly while those of the frozenthawed one remained constantly lower throughout the storage period. The torrymeter has been used to determine the freshness of meat or fish by measuring modifications in the electrical properties of tissues (Duflos et al., 2002). The permittivity and conductivity of meat were decreased with the increase of spoilage (Lougovois et al., 2003). Sung et al. (2013) found that torrymeter value was negatively

Table 2. Sensory evaluation of chicken thigh meat processed with different deboning conditions

\begin{tabular}{ccccccc}
\hline \hline \multirow{2}{*}{ Treatment } & \multicolumn{5}{c}{ Sensory parameter } \\
\cline { 2 - 6 } & Color & Flavor & Taste & Tenderness & Juiciness & Overall acceptability \\
\hline Fresh & $5.08^{\mathrm{x}}$ & $5.25^{\mathrm{x}}$ & $5.08^{\mathrm{x}}$ & $5.71^{\mathrm{x}}$ & $5.45^{\mathrm{x}}$ & $5.41^{\mathrm{x}}$ \\
Fresh-outside & $5.04^{\mathrm{x}}$ & $5.71^{\mathrm{x}}$ & $5.63^{\mathrm{x}}$ & $5.38^{\mathrm{x}}$ & $5.25^{\mathrm{x}}$ & $5.63^{\mathrm{x}}$ \\
Frozen-thawed & $4.38^{\mathrm{y}}$ & $3.54^{\mathrm{y}}$ & $3.54^{\mathrm{y}}$ & $3.46^{\mathrm{y}}$ & $3.04^{\mathrm{y}}$ & $3.04^{\mathrm{y}}$ \\
SEM $^{2}$ & 0.160 & 0.269 & 0.271 & 0.295 & 0.298 & 0.317 \\
\hline
\end{tabular}

${ }^{1}$ See the footnote of Table 1.

${ }^{2}$ Standard error of means $(n=24)$.

${ }^{\mathrm{x}, \mathrm{y}}$ Different letters within the same column differ significantly $(p<0.05)$. 
correlated to the count of total aerobic bacteria in duck breast meat. Therefore, it seems that the low torrymeter value of fresh-outside chicken compared to that of fresh one is caused by the higher count of total aerobic bacteria. In addition, freezing decreased the permittivity and conductivity of meat because the generation of ice crystals during freezing damaged the membrane of meat, causing the efflux of intercellular electrolytes and the influx of extracellular ones (Jung et al., 2011; Ghatass et al., 2008). As well as torrymeter, $\mathrm{K}$ value was introduced as an indicator of the degree of meat freshness (Saito et al., 2009). This value is obtained by measuring the proportion of inosine and hypoxanthine to the total amount of ATP and its degradation products. However, the K value is not reliable for differentiating between frozenthawed and fresh meat because the amount of ATP and its degradation products depend on the storageconditions (Lougovois et al., 2003). The study by Jung et al. (2011) confirmed that $\mathrm{pH}$ and $\mathrm{K}$ values did not provide satisfactory results for the differentiation of frozen-thawed breast fillets from fresh ones during storage.

\section{Conclusions}

Drip loss and sensory evaluation clearly differentiate the fresh chicken thigh meat from the frozen-thawed one. The torrymeter was found to be effective and simple to differentiate the fresh chicken thigh meat from frozenthawed or fresh-outside samples, and can, therefore, be implemented in industry.

\section{Acknowledgements}

This work was supported by a grant from the NextGeneration Bio Green 21 Program (No. PJ0081330), Rural Development Administration, Republic of Korea and partially supported from Korea Institute of Animal Products Quality Evaluation.

\section{References}

1. Ballin, N. Z. and Lametsch, R. (2008) Analytical methods for authentication of fresh vs. thawed meat - a review. Meat Sci. 80, 151-158.

2. Benjakul, S. and Bauer, F. (2001) Biochemical and physicochemical changes in catfish (Silurus glanis Linne) muscle as influenced by different freeze/thaw cycles. Food Chem. 72, 207-217.

3. Choe, J. H., Nam, K., Jung, S., Kim, B., Yun, H., and Jo, C. (2010) Differences in the quality characteristics between com- mercial Koreannative chickens and broilers. Korean J. Food Sci. An. 30, 13-19.

4. Dias, J., Nunes, M. L., and Mendes, R. (1994) Effect of frozen storage on the chemicaland physical properties of black and silver scabbard fish. J. Sci. Food Agric. 66, 327-335.

5. Duflos, G., Le Fur, B., Mulak, V., Becel, P., and Malle, P. (2002) Comparison of methods of differentiating between fresh and frozen-thawed fish or fillets. J. Sci. Food Agric. 82, 1341-1345.

6. Filgueras, R. S., Gatellier, P., Aubry, L., Thomas, A., Bauchart, D., Durand, D., Zambiazi, R. C., and Santé-Lhoutellier, V. (2010) Colour, lipid and protein stability of rhea americana meat during air- and vacuum-packaged storage: Influence of muscle on oxidative processes. Meat Sci. 86, 665-673.

7. Fischer, K. (2007) Drip loss in pork: Influencing factors and relation to further meat quality traits. J. Anim. Breed. Genet. 124, 12-18.

8. Fletcher, D. L. (1999) Broiler breast meat color variation, $\mathrm{pH}$, and texture. Poultry Sci. 78, 1323-1327.

9. Ghatass, Z. F., Soliman, M. M., and Mohamed, M. M. (2008) Dielectric technique for quality control of beef meat in the range $10 \mathrm{kHz}-1 \mathrm{kHz}$. Am. Eur. J. Sci. Res. 3, 62-69.

10. Han, I. K., Ha, J. K., and Lee, J. H. (2009) Growth and development of the academic societies and animal production in Korea, China and Asia over the last 50 years. Asian-Australas J. Anim. Sci. 22, 906-914.

11. Huff-Lonergan, E. and Lonergan, S. M. (2005) Mechanisms of water-holding capacity of meat: The role of post mortem biochemical and structural changes. Meat Sci. 71, 194-204.

12. Jeong, J. Y., Kim, G. D., Yang, H. S., and Joo, S. T. (2011) Effect of freeze-thaw cycles on physicochemical properties and color stability of beef semimembranosus muscle. Food Res. Int. 44, 3222-3228.

13. Jung, S., Lee, J. C., Jung, Y., Kim, M. K., Son, H. Y., and Jo, C. (2011) Instrumental methods for differentiation of frozenthawed from fresh broiler breast fillets. Korean J. Food Sci. An. 31, 27-31.

14. Jung, Y., Jung, S., Lee, H. J., Kang, M., Lee, S. K., Kim,Y. J., and Jo, C. (2012) Effect of high pressure after the addition of vegetable oil on the safety and quality of beef loin. Korean $J$. Food Sci. An. 32, 68-76.

15. Kim, C. J. and Lee, E. S. (2003) Effects of quality grade on the chemical, physical and sensory characteristics of Hanwoo (Korean native cattle) beef. Meat Sci. 63, 397-405.

16. KREI (2008) Agricultural Outlook 2008. Korea Rural Economic Institute.

17. Ledward, D. A. and MacFarlane, J. J. (1971) Some observation on myoglobin and lipid oxidation in frozen beef. J. Food Sci. 36, 987-989.

18. Lee, H. J., Lee, S. H., Yang, C. H., Lee, J. C., and Jo, C. (2012) Comparison of cut meat yield from two different breeds of broilers in Korea. Korean J. Poult. Sci. 39, 163-166.

19. Leygonie, C., Britz, T. J., and Hoffman, L. C. (2012) Meat quality comparison between fresh and frozen/thawed ostrich M. iliofibularis. Meat Sci. 91, 364-368.

20. Livingston, D. J. and Brown, W. D. (1981) The chemistry of 
myoglobin and its reactions. Food Technol. 35, 238-252.

21. Lougovois, V. P., Kyranas, E. R., and Kyrana, V. R. (2003) Comparison of selected methods of assessing freshness quality and remaining storage life of iced gilthead sea bream (Sparusaurata). Food Res. Int. 36, 551-560.

22. Renerre, M. and Labadie, J. (1993) Fresh meat packaging and meat quality. 39th Int. Cong. Meat Sci. Technol., Calgary, Canada, pp. 361-387.

23. SAS (2010) The SAS software for Windows (Release 9.1). SAS institute Inc., Cary, NC, USA.

24. Saito, K., Ahhmed, A. M., Kawahara, S., Sugimoto, Y., Aoki, T., and Muguruma, M. (2009) Evaluation of the performance of osmotic dehydration sheets on freshness parameters in colod-stored beef biceps fermoris muscle. Meat Sci. 82, 260265.
25. Sung, S. H., Bae, Y. S., Oh, S. H., Lee, J. C., Kim, H. J., and Jo, C. (2013) Possibility of instrumental differentiation of duck breast meat with different processing and storage conditions. Korean J. Food Sci. An. 33, 96-102.

26. Turhan, S., SuleUstun, N., and Bank, I. (2006) Effect of freezethaw cycles on total and heme iron contents of bonito (Sardasarda) and bluefish (Pomatomussaltator) fillets. J. Food Compos. Anal. 19, 384-387.

27. Vieira, C., Diaz, M. Y., Martínez, B., and García-Cachán, M. D. (2009) Effect of frozen storage conditions (temperature and length of storage) on microbial and sensory quality of rustic crossbred beef at different stages of aging. Meat Sci. 83, 398404.

(Received 2013.10.3/Revised 2014.1.7/Accepted 2014.1.20) 